\title{
Commentary: Sympathectomy for cardiomyopathy: It's a matter of nerves
}

\author{
Donald D. Glower, MD
}

\author{
From the Division of Cardiothoracic Surgery, Department of Surgery, Duke University Medical Center, Durham, \\ NC. \\ Disclosures: Author has nothing to disclose with regard to commercial support. \\ Received for publication Sept 6, 2019; revisions received Sept 6, 2019; accepted for publication Sept 10, 2019; \\ available ahead of print Sept 23, 2019. \\ Address for reprints: Donald D. Glower, MD, Duke University Medical Center, Box 3851, Durham, NC 27710 \\ (E-mail: Glowe001@mc.duke.edu). \\ J Thorac Cardiovasc Surg 2020;160:e147 \\ $0022-5223 / \$ 36.00$ \\ Copyright (c) 2019 by The American Association for Thoracic Surgery \\ https://doi.org/10.1016/j.jtcvs.2019.09.025
}

Coutinho e Silva and colleagues ${ }^{1}$ present data from a chronic rat model of dilated cardiomyopathy showing that bilateral sympathectomy minimized ventricular remodeling and impairment of ventricular performance. Although some of the benefits of sympathectomy have been seen in previous studies of dilated cardiomyopathy, this may be the cleanest and most insightful study to date, with a remarkably thorough combination of cardiac mechanics, histology, and biochemistry in chronic small animal study.

This study goes beyond demonstrating potential efficacy of bilateral sympathectomy to prevent remodeling due to cardiomyopathy in selected situations: this study provides some insight into the potential mechanisms by which sympathectomy may work. In particular, the mechanism of bilateral sympathectomy may be decreasing apoptosis, which in turn might explain decreased myocardial fibrosis. This mechanism is potentially different from that of angiotensin-converting enzyme (ACE) inhibitors and therefore could be synergistic along with ACE inhibitors or other therapies working by other mechanisms. The precise details of how sympathectomy decreases apoptosis were not elucidated.

There are limitations to these data. First, because of the limited time frame of the study, this study does not prove that sympathectomy permanently prevents remodeling as opposed to simply delaying remodeling. Second, the study does not establish the time window after the initiation of cardiomyopathy when sympathectomy is effective. In fact, these data do not demonstrate that sympathectomy can reverse long-established cardiomyopathy. Third, there are many different etiologies of cardiomyopathy, and it is yet to be seen which types of cardiomyopathies are more amenable to sympathectomy as opposed to others. Fourth, it was not shown whether sympathectomy would add any value in addition to or beyond what other therapies like ACE inhibitors can provide. Finally, the durability of the

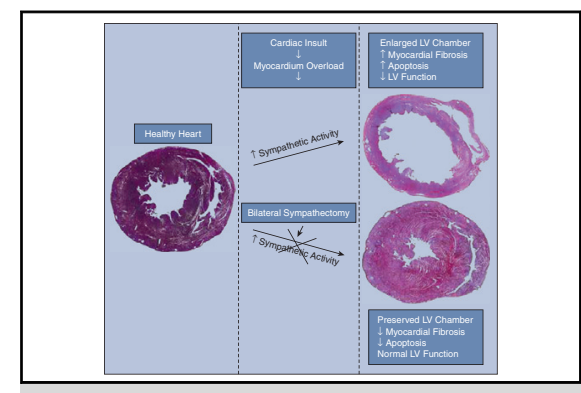

Proposed mechanism of bilateral sympathectomy in dilated cardiomyopathy.

\section{Central Message}

In a rat model of doxorubicin-induced cardiomyopathy, early bilateral sympathectomy decreased apoptosis and myocardial fibrosis.

See Article page e135.

sympathectomy in blocking remodeling due to cardiomyopathy was not demonstrated in this study beyond 8 weeks.

Although much work needs to be done to answer these questions, this study does suggest that bilateral sympathectomy might have clinical value in selected patients with early cardiomyopathy not responding to less-invasive therapies. Any insightful investigation will raise more questions than it answers, and the study of Coutinho e Silva and colleagues does just that.

Blocking the sympathetic nervous system either surgically or pharmacologically has been shown to have clinical benefit in reducing atrial or ventricular arrhythmias ${ }^{2}$ and in improving survival after myocardial infarction. ${ }^{3}$ Like those studies, this investigation suggests that preventing early adverse aspects of dilated cardiomyopathy may also be just a matter of nerves.

\section{References}

1. Coutinho e Silva RSC, Zanoni FL, Simas R, da Silva MHFM, Armstrong R Jr Correi CJ, et al. Effect of bilateral sympathectomy in a rat model of dilated cardiomyopathy induced by doxorubicin. J Thorac Cardiovasc Surg. 2020;160:e135-44.

2. Nielsen KC, Owman C. Control of spontaneous ventricular fibrillation during induced hypothermia in cats by acute cardiac sympathectomy. Acta Physiol Scand. 1969;76:73-81.

3. Hjalmarson A, Herlitz J, Malek I, Rydén L, Vedin A, Waldenstrom A, et al Timolol-induced reduction in mortality and reinfarction in patients surviving acute myocardial infarction. N Engl J Med. 1981;304:801-7. 